\title{
Perbedaan NaOH Terhadap Kualitas Gracilaria verrucosa, Greville, 1830 (Florideophyceae : Gracilariaceae)
}

\author{
Akmal Nasrulloh*, Rini Pramesti, Gunawan Widi Santosa \\ Departemen IImu Kelautan, Fakultas Perikanan dan IImu Kelautan, Universitas Diponegoro \\ Jl. Prof. H. Soedarto S.H, Tembalang, Semarang, Jawa Tengah 50275 Indonesia \\ ${ }^{*}$ Corresponding author, e-mail : akmalnsrllh@gmail.com
}

\begin{abstract}
ABSTRAK: Gracilaria verrucosa merupakan salah satu jenis rumput laut yang berpotensi sebagai penghasil agar bernilai tinggi. Senyawa ini banyak digunakan sebagai pengental atau penstabil makanan dalam industri makanan. Jenis ini umumnya ditemukan di alam maupun dibudidayakan di tambak. Faktor fisik lingkungan dan parameter perairan dapat mempengaruhi kualitas agar yang dihasilkan. Informasi tentang kualitas agar dari rumput laut yang tumbuh di laut masih sedikit ditemukan, sehingga diperlukan penelitian. Tujuan penelitian ini untuk mengetahui pengaruh variasi konsentrasi $\mathrm{NaOH}$ terhadap kualitas agar G. verrucosa. Metode ekstraksi dilakukan dengan merendam sampel dalam larutan alkali $(\mathrm{NaOH})$ hingga didapatkan agar, kemudian dikeringkan dan ditepung. Semua data dianalisis secara statistik yaitu normalitas, homogenitas dan two way ANOVA. Hasil ekstraksi agar didapatkan rendemen sebesar 18,44-20,35\%, kadar air 13,22-15,06\%, kadar abu 2,65-6,78\% serta kekuatan gel 55,18-210,26 g/ $\mathrm{cm}^{2}$. Hasil FTIR menunjukkan gugus galaktosa yaitu 3,6anhidro-L-galaktosa yang menandakan sampel mengandung komposisi agar. Hasil menunjukkan bahwa konsentrasi $\mathrm{NaOH}$ berpengaruh nyata terhadap rendemen, kadar abu dan kekuatan gel $(p<0,05)$ kecuali kadar air. Semakin tinggi konsentrasi $\mathrm{NaOH}$ maka rendemen, kadar air, kadar abu dan kekuatan gel akan semakin tinggi.
\end{abstract}

Kata kunci: Gracilaria verrucosa; Agar; Pelakuan Alkali; Laut, FTIR

\section{The Differences of NaOH on Gracilaria verrucose Greville, 1830 (Florideophyceae : Gracilariaceae)}

\begin{abstract}
Gracilaria verrucosa is one type of seaweed that has the potential to produce of high-value agar. This compound is much used as a food thickener or stabilizer in the food industry. This species is generally found in nature and cultivated in ponds. Factor of physical environmental and water parameter can affect the quality of produced agar. Information about quality of agar from seaweed that grows in the sea still rarely found, so research is needed. The purpose of this study was to determine the effect of different $\mathrm{NaOH}$ concentrations on the quality of agar $G$. verrucosa. The extraction method is done by soaking seaweed in an alkaline solution (NaOH) to obtain agar, then dried and turned into flour. All data were analyzed statistically with normality, homogenity and two way ANOVA. The results extraction of agar obtained yields 18,44-20,35\%, water content 13,22-15,06\%, ash content 2,65-6,78\% and gel strength 55,18-210,26 $\mathrm{g} / \mathrm{cm}^{2}$. FTIR results showed a galactose group of 3,6-anhydro-L-galactose which indicated the sample contained agar composition. The results showed that $\mathrm{NaOH}$ concentration significantly affected yield, ash content and gel strength $(p<0,05)$ except water content. The higher concentration of $\mathrm{NaOH}$ therefore the yield, water content, ash content and gel strength would be higher.
\end{abstract}

Keywords: Gracilaria verrucosa; Agar; Alkali Treatment; Sea, FTIR

\section{PENDAHULUAN}

Rumput laut adalah tumbuhan tingkat rendah yang tidak memiliki akar, batang, dan daun sejati, sehingga keseluruhan bagian tubuhnya dikenal dengan thallus (Ferawati et al., 2014). Tumbuhan ini memiliki kemampuan membentuk polisakarida berupa alginofit (penghasil alginat), 
karaginofit (penghasil karaginan) dan agarofit (penghasil agar) dari hasil proses fotosintesis (Hendrawati, 2016). G. verrucosa merupakan salah satu penghasil hidrokoloid berupa agar dan bersifat euryhaline, yaitu mampu beradaptasi terhadap lingkungan dengan perubahan salinitas yang besar (Fadilah dan Pratiwi, 2019). Tingkat salinitas yang dapat ditolerir sebesar 15-50 ppt (Rukmi et al., 2012).

Senyawa ini diperoleh melalui tahap berupa perendaman, ekstraksi, pemisahan agar dengan pelarutnya dan proses pengeringan. Setiap tahapan ini mempengaruhi hasil rendemen, kadar air, kadar abu dan kualitas gel (Distantina et al., 2007; Insan dan Widyartini, 2012). Proses ekstraksi ini dipengaruhi beberapa faktor, salah satunya yaitu konsentrasi alkali (Kusuma et al., 2013). Perlakuan alkali bertujuan mendapatkan agar dengan kekuatan gel yang tinggi (Darmawan et al., 2006).

Perlakuan alkali dalam proses ekstraksi ini dapat meningkatkan kualitas agar, namun informasi tentang kualitas agar dari tanaman jenis ini yang tumbuh di laut masih sedikit ditemukan. Tujuan penelitian ini untuk mengetahui pengaruh pemberian $\mathrm{NaOH}$ yang berbeda terhadap kualitas agar dari G. verrucosa.

\section{MATERI DAN METODE}

Materi yang digunakan pada penelitian ini adalah rumput laut G. verrucosa dari pantai Pok Tunggal, Gunung Kidul, Yogyakarta dan dikeringkan dibawah sinar matahari. Parameter perairan yang diamati yaitu suhu, salinitas, $\mathrm{DO}, \mathrm{pH}$, nitrat dan fosfat. Metode yang digunakan adalah experimental laboratories dengan perlakuan pemberian $\mathrm{NaOH}(0 \%, 6 \%, 8 \%, 10 \%)$ (Praiboon et al. 2006 dan Kusuma et al. 2013).

Sampel yang diperoleh dibersihkan dan dipucatkan dalam $1500 \mathrm{~mL} \mathrm{Ca}(\mathrm{OCl})_{2} 1 \%$ selama 2 jam. Pembuatan agar (Rath dan Adhikary, 2004 modifikasi Praiboon et al., 2006; Kusuma et al., 2013) dilakukan dengan ekstraksi. Sebanyak $50 \mathrm{~g}$ direbus pada suhu $\pm 80^{\circ} \mathrm{C}$ dalam $2000 \mathrm{~mL}$ air yang ditambahkan $\mathrm{NaOH}$ selama 2 jam. Sampel dicuci kemudian diblender dalam $1500 \mathrm{~mL}$ aquadest dengan penambahan $1 \mathrm{~mL} \mathrm{CH}{ }_{3} \mathrm{COOH}$ dan selanjutnya direbus pada suhu $\pm 90-95{ }^{\circ} \mathrm{C}$. Filtrat disaring dan dibiarkan membentuk gel pada suhu ruang dengan penambahan $\mathrm{KCl}$ sebanyak $12,5 \mathrm{~g}$. Agar yang diperoleh dikeringkan dibawah cahaya matahari kemudian ditepungkan.

Hasil yang didapat dianalisis secara statistik yaitu uji normalitas, homogenitas dan two way ANOVA. Parameter yang diamati adalah hasil rendemen, kadar air, kadar abu dan kekuatan gel. Analisis Fourier Tranform Infrared (FTIR) dilakukan untuk mengetahui keberadaan gugus fungsi molekulnya.

\section{HASIL DAN PEMBAHASAN}

Rendemen suatu bahan pangan berhubungan dengan nilai ekonomis bahan tersebut. Semakin tinggi rendemen suatu produk, maka nilai ekonomisnya akan semakin tinggi (Murdinah et al., 2008). Rendemen dihitung berdasarkan perbandingan antara berat tepung agar kering dengan berat rumput laut kering yang di ekstraksi. Hasil rendemen yaitu 18,44-20,35\% (Tabel 1). Hal ini menunjukkan rendemen yang didapat tidak memenuhi standar baku mutu yang lebih dari $25 \%$ (BSN, 2015). Hasil penelitian ini sedikit lebih tinggi dibandingkan dengan penelitian sebelumnya yaitu 6,31-13,89\% (Kusuma et al., 2013), 9,33-13,29\% (Santika et al., 2014) dan 9,65-10,10\% (Abidin et al., 2015). Hasil ANOVA menunjukkan peningkatan konsentrasi $\mathrm{NaOH}$ berpengaruh nyata $(p<0,05)$ terhadap rendemen. Rendemen tertinggi terdapat pada konsentrasi $\mathrm{NaOH} 10 \%$. Tingginya rendemen ini diduga adanya penambahan $\mathrm{NaOH}$ yang membuat proses penarikan ekstrak agar lebih mudah sehingga mempengaruhi rendemen yang dihasilkan (Santika et al., 2014). Hasil ini sesuai (Kusuma et al., 2013), bahwa tingginya rendemen diduga penambahan pemberian konsentrasi $\mathrm{NaOH}$ yang menyebabkan dinding sel rusak sehingga agar yang terakumulasi di dinding sel dapat ditarik keluar dengan mudah pada saat proses ekstraksi. Tinggi rendahnya rendemen agar juga dipengaruhi jenis rumput laut, proses ekstraksi, kondisi lingkungan, distribusi geografis dan musim panen (Santika et al., 2014; Ibrahim et al., 2015).

Hasil kadar air tepung agar yaitu 13,22-15,06\% (Tabel 1). Kadar air tertinggi diperoleh 
dengan perlakuan $\mathrm{NaOH} 10 \%$. Kadar air yang diperoleh sesuai (Santika et al., 2014) dan sedikit lebih tinggi pada beberapa jenis Gracilaria (Uju et al., 2018; Yolanda \& Agustono, 2018). Hal ini menunjukkan kadar air yang didapat pada penelitian ini sesuai dengan standar mutu yang dianjurkan yaitu kurang dari 22\% (BSN, 2015). Penambahan $\mathrm{NaOH}$ cenderung menyebabkan kadar air mengalami peningkatan. Hal ini diduga proses pengeringan yang dalam penelitian ini dengan dioven. Kelebihan dengan menggunakan oven yaitu suhu dapat dikontrol sehingga hasil yang diperoleh lebih maksimal karena tidak terjadi penurunan suhu. Hasil ANOVA pada kadar air menunjukkan konsentrasi $\mathrm{NaOH}$ tidak berpengaruh nyata. Hal ini diduga adanya pengaruh suhu $\left(100^{\circ} \mathrm{C}\right)$ pada saat pengovenan yang terlalu lama yaitu selama 6 jam, sehingga menyebabkan kandungan air dalam sampel banyak berkurang.

Analisis kadar abu bertujuan mengetahui secara umum kandungan mineral yang terdapat pada bahan yang digunakan (Murdinah et al., 2008). Kisaran kadar abu tepung agar yaitu 2,65$6,78 \%$ (Tabel 1). Hasil analisis statistika (ANOVA) menunjukkan peningkatan konsentrasi $\mathrm{NaOH}$ berpengaruh nyata $(p<0,05)$ terhadap kadar abu. Kadar abu menurun seiring dengan penambahan $\mathrm{NaOH}$. Hal ini diduga kandungan mineral pada tepung agar mengalami pengabuan yang sempurna, sehingga berpengaruh terhadap rendahnya hasil yang didapat. Hasil kadar abu yang diperoleh pada konsentrasi $6 \%$ melebihi batas mutu maksimal, sedangkan pada konsentrasi $8 \%$ dan $10 \%$ sesuai dengan baku mutu yang ditetapkan yaitu maksimal 6,5\% (BSN, 2015). Hal tersebut sesuai (Insan dan Widyartini, 2012) besarnya nilai kadar abu berkorelasi negatif dengan tingkat kemurnian agar dimana semakin tinggi kadar abu menunjukkan tingginya kadar mineral (bahan anorganik) sehingga semakin rendah kemurnian agar tersebut. Hal ini diduga faktor pencucian yang belum bersih setelah proses ekstraksi dan penyaringan yang kurang sempurna sehingga terdapat kotoran yang tidak tersaring dan terbawa.

Kekuatan gel merupakan salah satu parameter penting untuk mengukur mutu agar. Parameter ini digunakan sebagai penentu untuk menggambarkan banyaknya agarosa yang ada dalam tepung agar (Firdaus et al., 2015). Kisaran kekuatan gel yang didapat 55,18-210,26 g/cm (Tabel 1). Hasil penelitian ini masih lebih rendah dibandingkan dengan penelitian sebelumnya sebesar $493 \mathrm{~g} / \mathrm{cm}^{2}$ (Murdinah dan Sinurat, 2011), 144,74-483,89 g/ $\mathrm{cm}^{2}$ (Santika et al., 2014) dan $800-1000 \mathrm{~g} / \mathrm{cm}^{2}$ (Yolanda dan Agustono, 2018). Hasil penelitian ini sebagian sudah masuk dalam standar mutu yaitu sebesar $150-600 \mathrm{~g} / \mathrm{cm}^{2}$. Pada konsentrasi $\mathrm{NaOH} 10 \%$ mendapatkan hasil kekuatan gel terbaik sebesar $210,26 \mathrm{~g} / \mathrm{cm}^{2}$, sehingga hasil ini termasuk ke dalam standar tersebut, sedangkan konsentrasi lainnya belum termasuk dalam standar yang ditetapkan. Hasil analisis statistika (ANOVA), hubungan antara peningkatan konsentrasi $\mathrm{NaOH}$ diketahui berpengaruh nyata $(p<0,05)$ terhadap kekuatan gel. Kekuatan gel cenderung meningkat seiring bertambahnya $\mathrm{NaOH}$. Hal tersebut diduga pada proses perlakuan alkali ini, $\mathrm{NaOH}$ dapat menghilangkan kandungan sulfat yang terdapat pada rumput laut. Kandungan sulfat yang masih tinggi akan menurunkan kekuatan gel agar yang dihasilkan (Romenda et al., 2013).

Pita serapan pada gelombang $4000-1500 \mathrm{~cm}^{-1}$ menunjukkan pada gelombang sekitar 3400 $\mathrm{cm}^{-1}$ terdapat gugus hidroksil berupa ikatan hidrogen $(\mathrm{O}-\mathrm{H})$. Gelombang sekitar $2900 \mathrm{~cm}^{-1}$ menunjukkan adanya gugus alkana $\left(\mathrm{CH}_{3}\right.$ atau $\left.\mathrm{CH}_{2}\right)$ berasosiasi dengan metoksil dan gelombang sekitar $1600 \mathrm{~cm}-1$ terdapat gugus aldehida (-CHO). Pita serapan pada daerah sidik jari yaitu 1500$400 \mathrm{~cm}^{-1}$ menunjukkan pada gelombang sekitar $1380 \mathrm{~cm}^{-1}$ terdapat gugus ester sulfat dan gelombang sekitar $1070 \mathrm{~cm}^{-1}$ terdapat struktur senyawa galaktosa pada agar (Abidin et al., 2015).

Tabel 1. Kualitas Tepung Agar Gracilaria verrucosa dari Perbedaan Konsentrasi $\mathrm{NaOH}$

\begin{tabular}{ccccc}
\hline \multirow{2}{*}{ Parameter Uji } & \multicolumn{4}{c}{ Konsentrasi } \\
\cline { 2 - 5 } & $0^{*}{ }^{*}$ & $6 \%$ a) & $8 \%{ }^{\text {a) }}$ & $10 \%{ }^{\text {a) }}$ \\
\hline Rendemen (\%) & $18.44 \pm 0.31$ & $19.33 \pm 0.15$ & $20.15 \pm 0.17$ & $20.35 \pm 0.17$ \\
Kadar air (\%) & $13.22 \pm 1.71$ & $14.03 \pm 1.03$ & $14.81 \pm 1.25$ & $15.06 \pm 2.79$ \\
Kadar abu (\%) & $6.28 \pm 0.56$ & $6.78 \pm 1.51$ & $4.15 \pm 0.28$ & $2.65 \pm 0.29$ \\
Gel strength (\%) & $55.18 \pm 2.38$ & $141.02 \pm 3.57$ & $169.66 \pm 1.30$ & $210.26 \pm 0.21$ \\
\hline
\end{tabular}




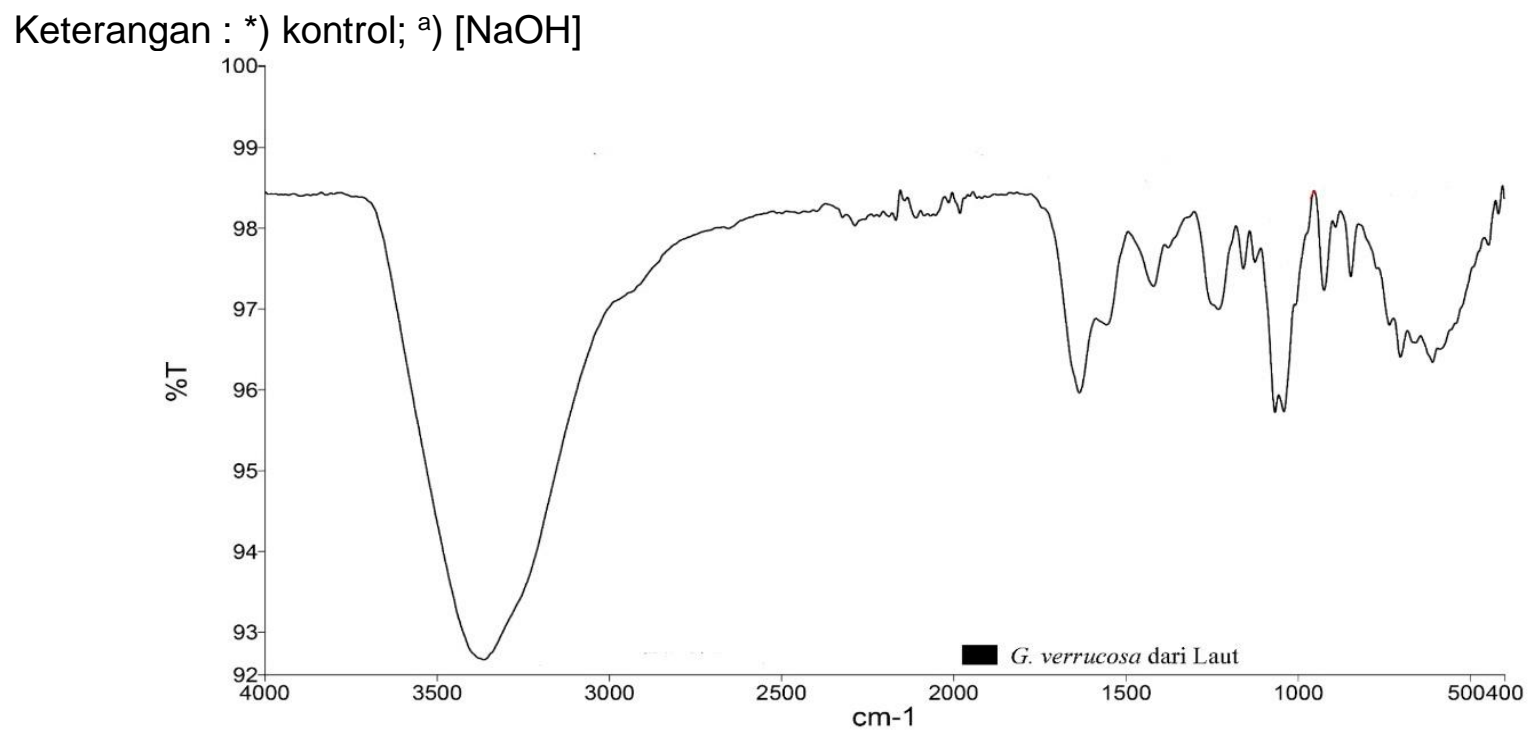

Gambar 1. Spektra IR Agar Hasil Ekstraksi Rumput Laut G. verrucosa

Hasil analisa FTIR ekstrak agar memiliki beberapa spektrum pita serapan.Spektrum IR pada Gambar 1 terlihat pada panjang gelombang $3366,83 \mathrm{~cm}^{-1}$ terdapat gugus hidroksil $(\mathrm{O}-\mathrm{H})$. Pada panjang gelombang $1634,78 \mathrm{~cm}^{-1}$ adanya gugus keton $(C=O)$ (Dachrianus, 2004). Panjang gelombang 1350,23 $\mathrm{cm}^{-1}$ terdapat gugus ester sulfat $(\mathrm{S}=0)$ (Abidin et al., 2015). Pada panjang gelombang 1100,68 $\mathrm{cm}^{-1}$ terdapat gugus eter (C-O-C) (Dachrianus, 2004) dan pada $950 \mathrm{~cm}^{-1}$ terdapat gugus spesifik 3,6-anhidro-L-galaktosa (C-O). Hasil tersebut menunjukkan agar mengandung komposisi ekstrak agar pada umumnya dengan adanya gugus galaktosa yaitu 3,6anhydro-L-galaktosa (Rasheed et al., 2019).

\section{KESIMPULAN}

Hasil penelitian menunjukkan peningkatan konsentrasi $\mathrm{NaOH}$ memberikan pengaruh $(p<0,05)$ terhadap kualitas agar rumput laut Gracilaria verrucosa. Semakin tinggi konsentrasi $\mathrm{NaOH}$ maka semakin tinggi rendemen (18,44-20,35\%), kadar air (13,22-15,06\%), kekuatan gel (55,18-210,26 $\left.\mathrm{g} / \mathrm{cm}^{2}\right)$ dan semakin rendahnya kadar abu $(6,78-2,65 \%)$.

\section{DAFTAR PUSTAKA}

Abidin, Z., M. Rudyanto \& Sudjarwo. 2015. Isolasi dan Karakterisasi Agarosa dari Rumput Laut Gracilaria verrucosa. Jurnal IImu Kefarmasian Indonesia, 13(1):69-75.

Badan Standarisasi Nasional (BSN). 2015. SNI 2802:2015 Agar-agar Tepung. Dewan Standarisasi Nasional. Jakarta. $14 \mathrm{hlm}$.

Darmawan, M., Syamdidi \& Hastarini, E. 2006. Pengolahan Bakto Agar dari Rumput Laut Merah (Rhodymenia ciliata) denga Pra Perlakuan Alkali. Jurnal Pascapanen dan Bioteknologi Kelautan dan Perikanan, 1(1):9-18.

Dachrianus. 2004. Analisis Struktur Senyawa Organik Secara Spektroskopi. Padang: Lembaga Pengembangan Teknologi Informasi dan Komunikasi.

Distantina, S., Fadilah, Dyartanti, E.R. \& Artati, E.K. 2007. Pengaruh Rasio Berat Rumput Laut Pelarut terhadap Ekstraksi Agar-Agar. Jurnal Ekuilibrium, 6(2):53-58.

Fadilah, S. \& Pratiwi, D.A. 2019. Regenerasi Rumput Laut Gracilaria sp. melalui Propagasi Secara Ex vitro. Jurnal Kelautan, 12(2):158-164. 
Ferawati, E., Widyartini, D.S. \& Insan, I. 2014. Studi Komunitas Rumput Laut pada Berbagai Substrat di Perairan Pantai Permisan Kabupaten Cilacap. Scripta Biologica, 1(1):55-60.

Firdaus, M., Prihanto, A.A. \& Nurdiani, R. 2015. Peningkatan Mutu Rumput Laut (Gracilaria sp.) Kering dengan Pencuci Drum. Journal of Innovation and Applied Technology, 1(2):118-123.

Hendrawati, T. Y. 2016. Pengolahan Rumput Laut dan Kelayakan Industrinya. UMJ Press: Jakarta, hlm.8.

Ibrahim, H.A.H., Beltagy, E.A., El-Din, N.G.S., Zokm, G.M.E., El-Sikaily, A.M. \& Abu-Elela, G.M. 2015. Seaweeds Agarophytes and Associated Epiphytic Bacteria Along Alexandria Coastline, Egypt, with Emphasis on The Evaluation and Extraction of Agar and Agarose. Revista de Biologia Marina y Oceanografia, 50(3):545-561.

Insan, A.I. \& D.S. Widyartini. 2012. Peningkatan Kualitas Produk "Agar" Rumput Laut Gracilaria gigas dengan Penambahan lota Karaginan Melalui Pemanasan Model "Smog Steam". Jurnal Litbang Provinsi Jawa Tengah, 10(2):157-167.

Kusuma, W.I., Santosa, G.W. \& Pramesti, R. 2013. Pengaruh Konsentrasi NaOH Terhadap Mutu Agar Rumput Laut Gracilaria verrucosa. Journal of Marine Research, 2(2):120-129.

Murdinah., D. Fransiska \& Subaryono. 2008. Pembuatan Bakto Agar dari Rumput Laut Gelidium rigidum untuk Media Tumbuh Bagi Mikroorganisme. Jurnal Pascapanen dan Bioteknologi Kelautan dan Perikanan, 3(1):79-88.

Murdinah \& Sinurat, E. 2011. Perbaikan Sifat Fungsional Agar-Agar dengan Penambahan Berbagai Jenis Gum. Jurnal Pascapanen dan Bioteknologi Kelautan dan Perikanan, 6(1):9199.

Praiboon, J., Chirapart, A., Akakabe, Y., Bhumibhamon, O. \& Kajiwara, T. 2006. Physical and Chemical Characterization of Agar Polysaccharides Extracted from the Thai and Japanese Species of Gracilaria. Science Asia, 32 (1):11-17.

Rasheed, I., Tabassum, A., Khan, U. \& Rehman, A. 2019. Fourier Transform Infrared (FT-IR) Spectroscopy of Agar from Red Seaweeds of Karachi Coast. International Journal of Biology and Biotechnology, 16(1):59-63.

Rath, J \& Adhikary, S.P. 2004. Effect of Alkali Treatment On The Yield and Quality of Agar from Red Alga Gracilaria verrucosa (Rhodophyta, Gracilariales) Occuring at Different Salinity Gradient of Chilika Lake. Indian Journal of Marine Sciences, 33 (2):202-205.

Romenda, A.P., Pramesti, R.\& Susanto, A.B.. 2013. Pengaruh Perbedaan Jenis Dan Konsentrasi Larutan Alkali Terhadap Kekuatan Gel dan Viskositas Karaginan Kappaphycus alvarezii, Doty. Journal of Marine Research, 2(1):127-133.

Rukmi, A. S., Sunaryo \& A. Djunaedi. 2012. Sistem Budidaya Rumput Laut Gracilaria verrucosa di Pertambakan dengan Perbedaan Waktu Perendaman di Dalam Larutan NPK. Journal of Marine Research, 1(1):90-94.

Santika, L.G., Ma'ruf, W.F. \& Romadhon. 2014. Karakteristik Agar Rumput Laut Gracilaria verrucosa Budidaya Tambak dengan Perlakuan Konsentrasi Alkali pada Umur Panen yang Berbeda. Jurnal Pengolahan dan Bioteknologi Hasil Perikanan, 3(4):98-105.

Uju, U., Santoso, J., Ramadhan, W. \& Abrory, M.F. 2018. Ekstraksi Native Agar dari Rumput Laut Gracilaria sp. dengan Akselerasi Ultrasonikasi pada Suhu Rendah. Jurnal Pengolahan Hasil Perikanan Indonesia, 21(3):414-422.

Yolanda, N.T. \& Agustono. 2018. Proses Ekstraksi dan Karakterisasi Fisika Kimia Bubuk Agar Gracilaria sp. Skala Laboratorium di PT. Java Biocolloid Surabaya. Journal of Marine and Coastal Science, 7(3):127-138. 